\title{
Sistemas de Conhecimentos Científicos e Tradicionais de formandos em Ciências da Natureza na Educação do Campo: Diálogos a partir da Teoria Ator-Rede
}

\author{
Scientific and traditional knowledge systems of nature sciences \\ undergraduates in Field Education: dialogues from the Actor-Network \\ Theory
}

\begin{abstract}
Luciana Resende Allain (luciana.allain@ufvjm.edu.br)
Programa de Pós-graduação em Educação em Ciências, Matemática e Tecnologia/ Universidade Federal dos Vales do Jequitinhonha e Mucuri
\end{abstract}

Ofelia Ortega Fraile (ofelia.ortega.fraile@gmail.com)

Programa de Pós-graduação em Educação em Ciências, Matemática e Tecnologia/ Universidade Federal dos Vales do Jequitinhonha e Mucuri

Luana Pereira Leite Schetino (luanabiocel@gmail.com)

Programa de Pós-graduação em Educação em Ciências, Matemática e Tecnologia/ Universidade Federal dos Vales do Jequitinhonha e Mucuri

Paulo Leandro Ramos (paulo_leandro_ramos@yahoo.com.br)

Programa de Pós-graduação em Educação em Ciências, Matemática e Tecnologia/ Universidade Federal dos Vales do Jequitinhonha e Mucuri

Janaina Boldt de Oliveira (janainabolt1@hotmail.com)

Programa de Pós-graduação em Educação em Ciências, Matemática e Tecnologia/ Universidade Federal dos Vales do Jequitinhonha e Mucuri

Resumo: A Educação do Campo, segundo os marcos normativos, deve trazer as especificidades dos sujeitos do campo e dos seus territórios, partindo da realidade local, das práticas culturais e do trabalho no campo, estabelecendo um diálogo entre os conhecimentos tradicionais e os científicos, o que seria uma educação contextualizada. No Ensino de Ciências, frequentemente, essa relação está restrita a trazer o cotidiano dos estudantes para a sala de aula sem estabelecer uma interação crítica entre tais conhecimentos. Este texto apresenta as inter-relações e os conflitos entre os sistemas tradicionais de conhecimentos e o conhecimento científico que ocorrem no âmbito da Licenciatura em Educação do Campo de uma universidade pública mineira. A partir da Teoria Ator-Rede buscou-se investigar o diálogo entre os conhecimentos vivenciados no processo formativo dos sujeitos. A partir de um grupo focal com formandos em Ciências da Natureza foram identificadas diferentes estratégias de translação realizadas pelos sujeitos e pelo curso a fim de desenvolver composições de interesses que agregassem os conhecimentos e as práticas das comunidades do campo aos conteúdos escolares das Ciências da Natureza, valorizando os conhecimentos tradicionais e expandindo os horizontes dos formandos quanto aos processos de produção e circulação do conhecimento científico.

Palavras-chave: Educação do campo; Teoria Ator-Rede; conhecimentos tradicionais. 
Abstract: Field Education, according to normative frameworks, should bring the specificities of the subjects of the field and its territories, starting from the local reality, cultural practices and work in the field and establishing a dialogue between traditional and scientific knowledge, which would be a contextualized education. In Science Teaching, this relationship is often restricted to bringing students' daily lives into the classroom without establishing a critical interaction between such knowledges. This text presents the interrelations and conflicts between traditional knowledge systems and scientific knowledge that occur within the scope of the Degree in Field Education of a public university in Minas Gerais. From the Actor-Network Theory, we sought to investigate the dialogue between the knowledge experienced in the formative process of the subjects. From a focus group with nature sciences undergraduates, different translation strategies were identified by the subjects and by the course in order to develop compositions of interests that would add the knowledge and practices of the communities of the field to the school contents of the Nature Sciences, valuing the traditional knowledge and expanding the horizons of the trainees regarding the processes of production and circulation of scientific knowledge.

Key words: Field Education; Actor-Network Theory; Traditional knowledge.

\section{INTRODUÇÃO}

Este texto é parte de uma pesquisa que tem como objetivo mais amplo investigar as inter-relações e os conflitos entre os sistemas tradicionais de conhecimentos e o conhecimento científico no atual contexto da educação do campo. Aqui apresentamos resultados referentes aos diálogos estabelecidos entre conhecimentos tradicionais e científicos, vivenciados no processo formativo de formandos na habilitação de Ciências da Natureza do curso de Licenciatura em Educação do Campo de uma universidade mineira. Cabe ressaltar que preferimos nos referir ao conhecimento científico e ao conhecimento tradicional, ambos como sistemas de conhecimentos, em vez de "saberes", buscando considerá-los de forma simétrica, sem hierarquizá-los em termos ontológicos.

\section{a. EDUCAÇÃO DO CAMPO E ENSINO DE CIÊNCIAS}

A Educação do Campo foi configurando-se como área de conhecimento com o avanço das lutas e conquistas dos movimentos sociais do campo pela reforma agrária e pelo direito à educação dos camponeses. Em contraposição à educação rural ou "ruralismo pedagógico", que surgiu na primeira metade do século XX e que procurava minimizar os efeitos do êxodo rural, a Educação do Campo se configura na interseção entre a educação popular e a educação em alternância e se caracteriza por ser pensada 
por e com os sujeitos do campo e não apenas para os sujeitos do campo (SILVA et al., 2019). A Educação do Campo se configura em harmonia com um projeto societário emancipatório dos povos do campo, quilombolas, ribeirinhos, caiçaras, raizeiros, indígenas e extrativistas. Para Caldart (2009, p. 39), ela "nasceu como uma crítica à realidade da educação brasileira, particularmente à situação educacional do povo brasileiro que trabalha e vive no/do campo". Nesse sentido, a Educação do Campo coaduna com a valorização dos sujeitos do campo e dos sistemas tradicionais de conhecimento que permanecem na memória e nas práticas culturais.

As Diretrizes Operacionais para a Educação Básica nas Escolas do Campo (BRASIL, 2002) ressaltam no artigo $2^{\circ}$, três elementos para construção das escolas do campo e, portanto, para a formação dos professores do campo, que são fundamentais para nossa pesquisa: (i) o compromisso do ensino com a realidade local e suas práticas culturais, (ii) os conhecimentos próprios dos sujeitos do campo em diálogo com os conhecimentos produzidos pela ciência e a tecnologia e (iii) a articulação com a temporalidade do campo. O desenvolvimento e a implementação desses três elementos na formação de professores de ciências da natureza vão dar lugar respectivamente ao que entendemos por (i) educação contextualizada, (ii) diálogo entre conhecimentos tradicionais e científicos e (iii) Pedagogia da Alternância. Elementos que ficaram registrados e normatizados em diversos documentos oficiais, tal como nos projetos político-pedagógicos das Licenciaturas em Educação do Campo implantadas em mais de 40 instituições federais de ensino superior no Brasil.

Quando os marcos normativos reforçam a importância de trabalhar questões da realidade do campo existem diferentes abordagens possíveis do que chamamos de (i) educação contextualizada. Cabe-nos perguntar o que entendemos por realidade e como ela se encaixa com o objetivo emancipatório da Educação do Campo. No Ensino de Ciências podemos identificar principalmente dois grandes tipos de abordagens para organizar os currículos de Ciências. Por um lado, encontram-se abordagens que buscam trazer o cotidiano dos estudantes para dentro da sala de aula, trazer fenômenos do dia a dia para, a partir deles, abordar os conteúdos supostamente universais das disciplinas de ciências, como explicitam Silva et. al. (2019, p. 230) “o cotidiano passa a ser considerado um instrumento motivacional, cujo objetivo é direcionar a atenção dos alunos para algo que é da convivência deles, por meio de exemplificações e 
ilustrações”. Portanto, nesse viés não existe um compromisso por problematizar a realidade e transformá-la para superar as desigualdades sociais ou para colocar em diálogo crítico os sistemas de conhecimento científico e tradicional. Na contramão dessas propostas, existem abordagens do Ensino de Ciências engajadas com o objetivo emancipatório da Educação do Campo, que problematizam a realidade e trazem (ii) os conhecimentos científicos, em diálogo com os conhecimentos tradicionais, como forma de superação das contradições socioambientais para a transformação da realidade. Essas são linhas que entrelaçam o Ensino de Ciências com as pedagogias críticas, especialmente a perspectiva freireana, a histórico-crítica e a da escola-comuna. Essas abordagens constituem a educação contextualizada no Ensino de Ciências, na qual, segundo Silva et al. (2019), o conhecimento científico acumulado é relacionado ao contexto do campo, contemplando nesse sentido

[...] um Ensino de Ciências que vá além das relações entre os conceitos científicos e o cotidiano dos alunos. Ou seja, por meio da problematização de situações cotidianas, levar o aluno a refletir as relações universais que estes conceitos estabelecem como composição da área de Ciências, para além do cotidiano, como superação deste (p.234).

Nesse sentido, o Ensino de Ciências na perspectiva freireana aborda a realidade de forma crítica, que segundo Paulo Freire $(2005$, p.95) “(...) é um pensar que percebe a realidade como processo, que a capta em constante devir e não como algo estático. Não se dicotomiza a si mesmo na ação. 'Banha-se' permanentemente de temporalidade cujos riscos não se teme". Conforme apontam Silveira e Miranda (2019), a Abordagem Temática Freireana é a tendência hegemônica dentre os artigos que versam sobre Educação do Campo publicados nos anais do Encontro Nacional de Pesquisa em Educação em Ciências (ENPEC) nas duas últimas décadas, o que reforça a relevância desta abordagem.

Existe um acúmulo de experiências e reflexões acadêmicas sobre o processo da investigação temática nas áreas específicas de ensino de física, biologia e geociências, as quais tomam o lugar/contexto dos estudantes problematizando o espaço vivido como ponto de partida para articular os conhecimentos locais/tradicionais com os conhecimentos científicos curriculares (FREIRE, 2005; DELIZOICOV et al., 2011; ORTEGA; COMPIANI, 2011; COMPIANI, 2013; PERNAMBUCO; PAIVA, 2013). Tais trajetórias de ensino e pesquisa se apresentaram como possibilidades para atender as especificidades da formação de professores do campo (MOLINA, 2014), sendo que 
parte das licenciaturas em Educação do Campo tomaram essas referências como parâmetros formativos, dentre elas a da universidade aqui pesquisada.

Por último, o terceiro elemento é a (iii) Pedagogia da Alternância. Segundo Rodrigues (2008) as primeiras experiências educativas em alternância no Brasil começaram no final da década de 1960, no Estado do Espírito Santo, e foram pouco a pouco se expandindo ao longo dos anos 1970. Esta proposta se articulou com a educação popular e as lutas sociais do movimento por uma Educação do Campo, protagonizadas principalmente pelo movimento dos Trabalhadores Sem Terra (MST) e pelos sindicatos rurais. Hoje temos uma diversidade de experiências de Educação do Campo pautada na Pedagogia da Alternância, entre elas estão as Escolas Família Agrícola (EFAs) de ensino fundamental II, também com ensino médio e técnico, Escolas Multisseriadas, Escolas Municipais Comunitárias Rurais, Escolas Estaduais Comunitárias Rurais e Escolas de Assentamento. Todas elas compartilham a caraterística de respeitar os tempos diferenciados das comunidades camponesas, tempos que estão relacionados com o trabalho (plantações, colheitas), clima (época de chuva e seca), distância entre a casa e a escola e práticas culturais. O calendário escolar se distribui em função dessas especificidades em Tempo Escola (TE) e Tempo Comunidade (TC), sendo que o TE é concentrado e vinculado ao espaço da escola e o TC é vinculado aos territórios nos quais vivem os educandos. A aprendizagem é contínua, sem rupturas, existindo uma relação interdependente entre TE-TC, apenas mudam os lugares de ensino-aprendizagem e as estratégias e instrumentos de ensino.

Com o projeto emancipatório da Educação do Campo se fez necessário a formação superior de professores/educadores do Campo, que também segue os moldes da Pedagogia da Alternância, dando lugar aos cursos de Licenciatura em Educação do Campo (LEC). Na universidade pesquisada também se desenvolve a formação em diferentes tempos e espaços, o Tempo Universidade (TU) e o Tempo Comunidade, o que possibilita o estudante estar na universidade e na sua comunidade, permitindo que o mesmo não abandone sua vivência, trabalho, relações familiares e vínculos culturais com o território, pois a alternância permite que o estudo científico da universidade dialogue com a sua realidade e os conhecimentos tradicionais.

As propostas formativas postas pelo projeto de curso da LEC da universidade estudada trazem à tona dimensões dialógicas e políticas e é diante dessas questões que 
propomos seguir, por meio da Teoria Ator-Rede, a prática de formação desses professores do campo a partir da perspectiva freireana para o Ensino de Ciências.

\section{A TEORIA ATOR-REDE COMO MARCO TEÓRICO}

Para Latour (2004) a Teoria Ator-Rede consiste em descrever as realidades enquanto redes de associações entre elementos humanos e não humanos, observar e identificar as redes que se entrelaçam e descrevê-las. Portanto, a TAR é uma teoria sociológica que se difere das outras pela sua maneira de enxergar o social. Para a TAR as realidades se formam através de ligações entre atores, levando em consideração os interesses que esses possuem.

Inicialmente é preciso diferenciar o conceito de ator da TAR do ator social da sociologia clássica. Esta última considera unicamente o homem como ator social. Para a TAR, ator é tudo aquilo que age sobre o mundo. Por isso usaremos neste trabalho o termo actante (CALLON, 1999), para designar os elementos humanos ou não-humanos que se associam em rede, formando as realidades que estão sendo estudadas. Analisar de forma simétrica actantes humanos e não humanos, dando a eles pesos equivalentes na análise sociológica é o que Latour (1994) chama de Princípio da Simetria Generalizada.

A interligação entre os actantes produz as redes, que, para Moraes (2004) se estabelecem por fluxos, circulações, alianças e movimentos. Para a autora, as redes não se estabelecem por si só, mas são compostas por séries heterogêneas de elementos animados ou inanimados, conectados, agenciados. Além disso, um actante por si só pode fazer o papel de uma rede e uma rede pode atuar como um único actante, dependendo da perspectiva de análise adotada. Um ator-rede é, portanto, um actante e uma rede, ao mesmo tempo. Toda e qualquer ação que um actante venha a fazer deve deixar marcas ou influenciar outros actantes a agirem. Se uma ação não deixa marcas, isto é, não causa transformações, então ela não deve ser considerada na análise.

Não há como negar as diferenças entre os actantes, mas ao invés de tratar os atores separadamente, é possível considerá-los a partir de suas relações (LATOUR, 1994; MORAES, 2004). Tais relações são fruto de processos de translação (LATOUR, 2000), conceito central neste trabalho. A translação diz respeito a deslocamentos de objetivos, de interesses dos actantes envolvidos em uma controvérsia. É preciso 
ressaltar que, para a TAR, os fatos são sempre fabricados, são fatos feitos (LATOUR, 2012). Questões “de interesse" são questões discutidas, controversas, interessantes e podem ser encontradas em todos os lugares e podem vir a se tornar questões "de fato", em outras palavras, podem ser encerradas as discussões e chega-se a uma conclusão em que todos os actantes concordem, esfriando assim a controvérsia.

Os diversos interesses dos actantes é que fazem com que eles se associem em rede ou se dissociem das redes, por meio dos processos de translação. Transladar é ao mesmo tempo transcrever, transpor, descolar, transferir e, portanto, transportar transformando (LATOUR, 2000). Ao conjunto de translações ocorridas na análise de um determinado fenômeno dá-se o nome de composição de interesses. Latour (2000) assevera que o processo de translação demanda a habilidade política do actante de mobilizar e amarrar juntos cada vez mais elementos (humanos e não humanos) em uma cadeia de elos fortemente unidos entre si. Para mobilizar e manter juntos os actantes é preciso "fazer interessar" diferentes grupos, mantendo coeso o sistema de alianças já construído e associando-se a novos e inesperados aliados, incluindo os recursos humanos e não-humanos. Estes processos geram translações em cadeia, que podem transformar "o conjunto justaposto de aliados num todo que atue com unicidade", ou seja, uma máquina. O autor lembra que máquina é, antes de tudo, “maquinação, estratagema, um tipo de esperteza em que as forças usadas mantêm-se mutuamente sob controle, de tal modo que nenhuma delas possa escapar do grupo" (LATOUR, 2000: p. 212).

Portanto, transladar significa deslocar objetivos, interesses, dispositivos, seres humanos. Implica desvio de rota, invenção de um elo que antes não existia. As cadeias de translação, isto é, as composições de interesse, referem-se ao trabalho pelo qual os actantes modificam, deslocam e transladam os seus vários e contraditórios interesses (FREIRE, 2006).

Neste trabalho buscamos identificar as translações e as composições de interesse envolvidos nos processos formativos dos formandos em Ciências da Natureza na Licenciatura em Educação do Campo de uma universidade pública localizada em Minas Gerais.

\section{PROCEDIMENTOS METODOLÓGICOS DA PESQUISA}


A pesquisa fez uso de instrumentos qualitativos de coleta de dados, distribuídos em duas etapas: um levantamento por meio de questionário e um grupo focal. $\mathrm{O}$ questionário continha em sua maioria questões fechadas, destinado aos estudantes que estavam cursando o último módulo do Tempo Universidade no primeiro semestre de 2019. Esta escolha se deu em razão de os mesmos terem mais experiências acumuladas nos processos formativos da Educação do Campo e de já terem suas expectativas profissionais mais claras, em função da iminente formatura no curso. Depois da aplicação dos questionários convidamos os mesmos sujeitos para fazerem parte de um grupo focal, com o objetivo de aprofundar suas percepções. Segundo Barbour (2009), entrevistas com grupos focais são adequadas a estudos que buscam entender atitudes, preferências, necessidades e sentimentos individuais e entre grupos. $\mathrm{O}$ grupo focal foi conduzido com 12 participantes, uma moderadora e uma observadora de fluxo e de clima. Ocorreu em julho de 2019, durante o Tempo Universidade (TU), teve duração de aproximadamente uma hora e trinta minutos, foi gravado em áudio e transcrito na íntegra para posterior análise de seu conteúdo. Para não serem identificados, os nomes dos sujeitos pesquisados foram substituídos por pseudônimos.

\section{a. PERFIL DOS SUJEITOS DA PESQUISA}

Ao analisar os dados do questionário foi possível mapear o perfil dos estudantes. Com isso observamos que, dos 12 questionários analisados, apenas um estudante residia em zona urbana, sendo os demais residentes da zona rural. Com relação à faixa etária, seis estudantes possuíam idade entre 18 a 22 anos, um estudante entre 23 a 26, um estudante entre 27 a 30, um estudante entre 31 a 34 e três estudantes com idade acima de 35 anos. Verificamos que a maioria dos formandos do curso eram do sexo feminino, sendo apenas um do sexo masculino. Com relação às atividades de ensino na universidade, todos os estudantes atuavam em estágios curriculares, e a maioria teve experiências no PIBID-Diversidade e Residência Pedagógica. A maioria das escolas nas quais eles estagiavam se localizavam na zona rural, outras se caracterizam como escolas do campo por receber estudantes da zona rural. Além da atuação em escolas, nove dos estudantes atuavam em atividades educativas em suas comunidades como ensino religioso, ensino voluntário e ações em organizações sociais. Portanto, os dados

sugerem que os estudantes eram, em sua maioria, mulheres do campo engajadas com coletivos socioeducativos, com funções de cuidados familiares, ativas em suas 
comunidades e com experiências em projetos acadêmicos que envolviam as escolas do campo.

\section{COMPOSIÇÕES DE INTERESSE NO DIÁLOGO ENTRE OS SISTEMAS DE CONHECIMENTO TRADICIONAL E CIENTÍFICO}

Os dados do grupo focal apontam uma série de translações realizadas pelos estudantes e pelo próprio curso de Licenciatura em Educação do Campo no sentido de potencializar os diálogos entre os conhecimentos científicos e os tradicionais, como passaremos a descrever a seguir.

Ao serem perguntados no questionário e no grupo focal sobre que características deve ter um bom professor de ciências nas escolas do campo, grande parte dos sujeitos pesquisados afirmaram que o bom professor é aquele que parte do contexto do estudante e que valoriza a sua realidade, a sua identidade, que integra o conhecimento científico ao conhecimento tradicional. Luiza aponta as dificuldades que os estudantes normalmente têm em fazer relações entre os conceitos científicos e sua realidade, conforme se vê no trecho abaixo:

na minha regência eu dei, levei para a sala de aula um experimento de química, super fácil, ham...onde eles teriam que fazer uma mistura e calcular a densidade daquela mistura. (...) e eu tinha levado o pó de café, o açúcar, a água, o sal ...e uma moça, na verdade uma menina, falou que fazia isso em casa todos os dias. (...) E foi a partir dessa questão, dessa fala dela ((menina)) que eu fui explicar para ela que tudo que a gente aprende dentro da ciência, os conceitos que a gente aprende em física, química, biologia, português e matemática, estão todos interligados no cotidiano, eles vivem isso o tempo todo, mas para eles, o que ensinam na escola não tem nada a ver, ou eles nem conseguem enxergar que eles fazem isso o tempo todo, sabe? (Luiza)

Neste trecho identificamos as dificuldades da professora em tornar o ensino dos conceitos científicos algo significativo para a vida cotidiana dos estudantes. Para vencer tais dificuldades, observamos o uso de diferentes translações utilizadas pelos professores em formação para aproximarem os conhecimentos científicos aos saberes dos estudantes. Por exemplo, ao pedirmos explicações mais detalhadas sobre como esse processo de aproximação se dá na sala de aula, Joana coloca que:

Essa integração, por exemplo, misturar coisas que a gente já tem na comunidade, com conteúdos que a gente tem aqui na universidade. Assim...eu vou citar trabalhos em química, mas tem outros também...a gente trabalhou com a produção de farinha de milho, que tinha conteúdos específicos de química. Então eu acredito que seja uma maneira mais fácil de talvez o aluno "pegar" o conteúdo, para aprender lá a fermentação, no 
processo de farinha de milho, ou pode ser também, farinha de mandioca..."(Joana )

Latour (2001) explica que uma das translações mais comuns que ocorre no curso de uma dada ação é oferecer uma espécie de atalho para o objetivo pretendido. Ao perceber que o caminho para atingir os objetivos das pessoas está bloqueado, os actantes não tentam convencê-las a se afastar de seus objetivos, mas se oferecem para guiá-las por um desvio curto e bem sinalizado, que as fará chegar mais depressa aos seus interesses; como se dissesse: "se você desviasse um pouquinho...". Neste desvio o actante estará atendendo aos seus próprios interesses. No caso analisado, o objetivo final do professor é articular os conteúdos curriculares com a realidade dos sujeitos do campo, que o estudante compreenda o conceito de fermentação porque é um processo que faz parte da vida dele, da sua identidade camponesa, mas também que consiga aplicá-lo nos mais diferentes contextos, e não que ele saiba apenas repetir memoristicamente o que é fermentação. Percebemos que, ao utilizar exemplos das práticas culturais e dos modos de produção no campo, como a produção de farinhas por exemplo, o professor busca mobilizar esse conhecimento de mundo do estudante para atender aos seus objetivos pedagógicos, quais sejam, o de ensinar o processo de fermentação. Em vez de abordar o conteúdo científico de maneira descontextualizada da realidade dos estudantes, o professor utiliza de uma estratégia de translação, produz um desvio, busca na realidade dos estudantes, nas suas práticas culturais, exemplos que possam ressignificar os conceitos científicos.

Ainda buscando esclarecer como buscam relacionar a realidade dos estudantes com os conceitos científicos curriculares, Lucia coloca que:

Quando eu falo da realidade do meu aluno, é também trazer isso, coisas do cotidiano que eles fazem e a partir disso eu ensinar para eles os conceitos de física, ou igual eu também fiz, sobre arrastar objetos. Essa questão de um plano liso, um plano com atrito, força, Newton, ensinar para eles que quando eles ajudam a mãe a tirar uma mesa, empurrando, que eles estão fazendo uma força, que as Leis de Newton estão ali...sabe...e o que eu achei assustador, é que eles não tinham nem noção. (Lucia)

Neste trecho é possível identificar diferentes mobilizações de mundo acionados pela formanda para explicar conceitos relacionados à cinética. Neste exemplo, Lucia acionou uma rede que exerce influência sobre o mundo do aluno, arremessando-se em espaços e tempos distantes. Quando uma rede se torna suficientemente durável, suas translações são estendidas a outros locais, tempos e domínios por meio de processos de 
mobilização (FENWICK; EDWARDS, 2012, p. XII). Essa ação à distância também é permitida por um conjunto de coisas a que Latour (2000, p. 368) chamou de "móveis imutáveis", que funcionam como delegados de outras redes, estendendo seu poder por mover-se em diferentes espaços e trabalhando para transladar entidades para comportarem-se de modo particular. Latour (2001) explica que a mobilização consiste em trazer juntos elementos distantes física e temporalmente. No exemplo acima Lucia mobiliza Newton, força, o atrito, o plano liso e o inclinado, utilizando uma situação cotidiana que é empurrar uma mesa. Lucia busca partir de situações simples do cotidiano do aluno para mobilizar coisas que estão distantes no tempo e no espaço. Lucia mobiliza diferentes conceitos científicos, distantes no tempo e no espaço e os aciona para analisarem uma situação do "aqui e agora". Ao mundo dos estudantes outras entidades foram mobilizadas.

Questionados quanto ao papel do curso de Licenciatura em Educação do Campo na valorização dos conhecimentos tradicionais, os formandos relataram como as metodologias e concepções pedagógicas do curso ajudaram a fortalecer a identidade camponesa dos seus estudantes. Do ponto de vista da TAR identificamos translações realizadas pelo próprio curso, no sentido de formar professores de Ciências Naturais comprometidos em dialogar com as realidades do campo, a partir do conhecimento científico. Maria relata que:

\begin{abstract}
(...) os conhecimentos populares, ancestrais e tradicionais foram os pilares para construir toda nossa TEORIA ((parece exaltada)), todos os nossos trabalhos acadêmicos que a gente fez até hoje, a gente partiu da:: comunidade, partiu do cultural para o científico, partiu de um saber popular para:: um saber científico, entende? Quando eu fui contar a história do professor da minha comunidade, de uma pessoa importante da MINHA comunidade, entende que eu peguei minha vida, minha vivência, meu cotidiano, minha cultura, minha história e eu escrevi ela... e então eu fiz um texto teórico, que é acadêmico, é:: para fazer esse trabalho de botânica ou para fazer o trabalho de química, eu peguei uma produção de sabão, praticamente todas as mulheres e todas as... eu, eu faço qualquer coisa, porque eu vejo a minha mãe fazendo, a maioria das adolescentes da minha comunidade sabem fazer ou ajudam as mães em casa a fazer, então tipo é uma coisa cultural, então eu diria que:: toda a minha cultura, todo o meu saber popular, hoje ele é científico, porque a LEC me permite fazer isso né:: e eu acho que parte disso, eu nunca fiz um trabalho é:: científico aqui no curso sem que o pilar ou o objeto de pesquisa não fosse algo da minha comunidade. (Maria)
\end{abstract}

Essa translação que valoriza as práticas culturais e os conhecimentos tradicionais das comunidades camponesas é coerente com o projeto emancipatório da Educação do Campo, que busca gerar oportunidades aos estudantes de continuar tendo um vínculo e 
identidade camponeses. Poderíamos dizer que essa é uma translação que os movimentos sociais têm pautado para ela acontecer nas universidades, de forma que a academia legitima a presença e circulação de conhecimentos tradicionais. Na Educação do Campo os movimentos sociais são actantes fundamentais desde a origem das lutas por educação no campo até a institucionalização das licenciaturas. Na LEC da universidade estudada, eles têm um protagonismo formal no Conselho Consultivo que discute questões inerentes à Licenciatura e propõe temas transversais da realidade local para articular disciplinas, TU e TC, consolidando seu papel na rede de actantes locais. Por outro lado, as metodologias de ensino do TC, como os trabalhos das disciplinas no TC, as Práticas de Ensino e o Trabalho Interdisciplinar do TC, são artefatos, ou seja, actantes não humanos que atuam na rede propiciando a interação entre conhecimentos tradicionais e conhecimentos científicos. Entendemos que os movimentos sociais por uma Educação do Campo historicamente têm provocado uma translação que "remaneja interesses e objetivos" (LATOUR, 2000) na academia alistando intelectuais comprometidos com os objetivos das lutas pela terra e as pedagogias crítico-transformadoras com a táctica de criar um novo grupo de ensino-pesquisa-extensão que é o da Educação do Campo.

Outro tipo de translação que emergiu das análises foi a interação do conhecimento científico com o tradicional nas famílias dos educandos da LEC. No relato de Soraya aparece tal interação durante os trabalhos de TC da disciplina de Genética. A partir da observação de fenômenos naturais na horta, a estudante estabelece um diálogo com sua mãe:

\begin{abstract}
E foi aquela felicidade e ela trouxe as abóboras e me mostrou.... e perguntou porque que tinha dado duas abóboras diferentes num único pé de abóbora? Eu fui tentar explicar um pouquinho que pode ter sido o fato do polinizador ter pegado o pólen de uma planta e levado para outra e ocorrido o cruzamento, né. E que tem toda uma questão genética e agora eu posso chegar lá e explicar para ela, porque agora eu estou fazendo genética, mas assim ela vivenciou também o meu trabalho e eu fiquei boba, porque ela tinha interesse, ela até me falou que as abelhas que estavam indo na flor dela, era diferente das que estavam indo no meu pé de mamão e tudo isso sabe...foi fantástico e foi a primeira vez que ela se envolveu tanto no meu trabalho, por que a gente faz uns trabalhos que para eles são esquisitos ((risada)) é uma coisa completamente fora da realidade deles. (Soroya)
\end{abstract}

Os trabalhos das unidades curriculares durante o Tempo Comunidade buscam estabelecer uma interação problematizadora entre os sistemas de conhecimento científico e tradicional. Por vezes essas interações são "tranquilas" se complementam, suscitam curiosidade, olhares críticos sobre a realidade, por outras, aparecem tensões e 
controvérsias, que nem sempre são resolvidas como forma de superação das contradições.

Nesse sentido, alguns dos exemplos citados, como o da cinemática, entre outros, mostram um desvio entre o projeto de educação contextualizada, com perspectiva freireana, para um Ensino de Ciências com o cotidiano como ponto de partida. Podemos analisar que os artefatos tecnológicos da LEC, que no nosso caso são as metodologias pedagógicas da educação do campo, sofrem transformações dentro da rede de actantes envolvidos que têm interesses e concepções de mundo/educação embutidos neles. Como foi relatado anteriormente, no campo do Ensino de Ciências circulam diferentes visões de como trabalhar com a realidade do estudante. Entendemos que tal desvio envolve uma rede ampla e complexa de atores humanos e não humanos. Dentre os atores humanos, encontramos docentes da LEC com diferentes referenciais teóricometodológicos freireanos e não freireanos, professores das escolas que acompanham estágios e outros projetos, que conhecem ou não conhecem a Educação do Campo; e atores não humanos como textos, metodologias de sala de aula não freireanas, conceitos polissêmicos do ensino de ciências como "educação contextualizada", bolsas do PIBID ou Residência Pedagógica, que permitem aprofundar nas metodologias freireanas apenas a uma parte dos estudantes da LEC.

Na unidade curricular "Práticas de Ensino" também se dão interações entre os sistemas de conhecimento que são muito interessantes. A disciplina consiste em dois Encontros de Tempo Comunidade nos Polos de Alternância, que se localizam em municípios que agregam estudantes de comunidades rurais e quilombolas próximas. A disciplina se organiza com dois encontros nos quais os professores da LEC se deslocam até os territórios dos educandos, sendo um ou dois professores responsáveis por cada polo durante um ano. Os estudantes se agrupam por proximidade geográfica e participam juntos com estudantes dos diferentes períodos e habilitações, proporcionando assim interações interdisciplinares. Cada "Prática de Ensino" tem um tema que é transversal a todas as disciplinas do período letivo. Temas como agroecologia, as escolas do campo ou o trabalho e educação, são alguns exemplos de eixos que são definidos junto com o Conselho Consultivo da LEC. Durante o primeiro encontro é realizado um diagnóstico participativo e a leitura e discussão de um texto acadêmico relacionado com o tema transversal. A partir das discussões é elaborado um 
planejamento por parte dos educandos para realizar uma ação educativa com a comunidade e/ou com a escola de uma das comunidades de estudantes da LEC. Durante 4-6 semanas os estudantes organizam a atividade em grupos de trabalho junto com uma comunidade, articulando lideranças locais, movimentos sociais, escola e outras instituições. No segundo encontro acontecem as atividades, que podem ser desde rodas de conversa, feiras de saberes, seminários, oficinas, apresentações culturais, palestras, exposições, etc. A fala de Joana nos permite reforçar a compreensão do papel híbrido dos estudantes na rede, eles para além de vivenciarem junto com a família a interação entre conhecimentos tradicionais e acadêmicos, como vimos no relato de Soraya, também promovem interação com e na comunidade, em uma via de mão dupla.

Essa última prática de ensino da gente, dessa trilha que a gente fez. Não tinham alunos da escola, a gente fez com pessoas da comunidade, a noite a gente fez a noite cultural, a gente teve uma participação pequena, nós esperávamos uma participação maior, mas foi muito bom! A gente procurou levar os contos, os cantos, os casos, levamos uma comida típica, as festas envolvem muito os caldos de mandioca, a gente fez a noite, com aquele friozinho... para a comunidade mesmo, a gente nunca leva só para dentro da escola, a gente envolve a comunidade. (Soraya)

No relato de Lucas sobre a mesma prática de ensino podemos identificar como os estudantes durante as Práticas de Ensino estabelecem elos de alianças entre os atores protagonistas dos conhecimentos tradicionais (comunidade) e os atores que detêm os conhecimentos científicos (especialistas que trabalham nos parques):

Também fizemos um passeio interpretativo pela trilha, que também foi um trabalho, que...e...trabalhamos a história, para apresentar os grupos nativos, quem construiu a trilha foram os escravos, os garimpeiros e também as tropas...tinha muita interdisciplinaridade, porque...durante o passeio, muitas pessoas chegaram para conter seus causos, assim...eram pessoas muito velhinhas da comunidade, algumas delas nem tinham ido para a escola, mas estavam trazendo elementos para nós e valores para a comunidade e... tinham pinturas rupestres, também tinham casos sobre as chegadas dos limites das propriedades, o território perdeu sua identidade e começou a ser propriedade, como a natureza mudou... Foi um grande aprendizado, em um passeio nós trabalhamos tantas coisas, a gente trabalhou a Biologia e a geologia, também tinham pessoas do parque que iam acompanhando, pois era uma área de... preservação. Ele contaram muitas coisas também sobre a biologia, sobre a fauna, a flora...então foi uma coisa muito rica a partir de um passeio, tinham muitas pessoas da universidade e da comunidade ali também. (Lucas)

Finalmente, na contribuição de Maria podemos observar como os estudantes da LEC se transformam num actante híbrido que já não faz mais parte do actante "comunidade" nem do "especialista" da universidade.

Meu irmão....ele tem curiosidade em me perguntar as coisas, e eu sempre tento mostrar para ele, porque ele se refere assim: “Ah tá, porque agora você 
está na Universidade, é diferente", e daí eu falo com ele e tento mostrar para eles que não é...Eu chego lá com um trabalho universitário para fazer, mas eu vou fazer a partir da MINHA REALIDADE. Eu fiz um trabalho de Zoologia e Botânica, observando um pé de mamão do meu quintal, então eu mostro para ele que não é diferente, eu apenas estou aprofundando. (Maria)

Configura-se assim um novo tipo de actante que integra o diálogo entre conhecimentos científicos e tradicionais, um diálogo complexo, cheio de tensões, conflitos e contradições que a seguir analisamos.

\subsection{CONFLITOS ENTRE SISTEMAS DE CONHECIMENTOS}

\section{TRADICIONAIS E CIENTÍFICOS}

Apontamos acima alguns tipos de translações as quais caracterizam os diálogos entre os conhecimentos tradicionais do campo e o conhecimento científico curricular da LEC. No entanto, observamos, em alguns contextos, a presença de discordâncias entre os conhecimentos científicos e os conhecimentos tradicionais, conforme se vê na fala de Ivana:

(...) quando a mulher entra no período menstrual não se faz doce mole ou sabão, não chega no ponto o doce ou o sabão... é:: essa senhora falou assim comigo:: sobre o calor do corpo, o humor dela, entende? Então assim quando eu coloquei isso no meu trabalho, tipo a professora riu porque ela quis saber disso depois né:: mas eu falei é a explicação, e tipo não tem fundamentação nenhuma teórica em relação a isso, sabe? NÃO EXISTE... Se tiver alguém estranho na sua casa... Não pode ver você fazendo sabão... Pode ter mal olhado, então não pode deixar pegar... E tipo, muito disso é real, sabe por quê? Porque eu já vi acontecendo, sabe:: da minha mãe está fazendo o sabão e o sabão está dando certo e aí chegou a vizinha e olhou pro sabão e daqui a pouco o sabão coalhou assim, de uma forma ((eufórica)) tipo... são coisas que a gente vivencia mas que não tem explicação teórica ou científica, entende? E aí sempre vai haver conflito... (Ivana)

Segundo Latour (2000) a tecnociência é definida como todos os elementos amarrados ao conteúdo científico. Esse conteúdo agrega um número fantástico de elementos amarrados para uma alegação/afirmação científica ou as tecnologias/artefatos. Dentre esses elementos se encontram as literaturas, laboratórios, grupos de interesses, grandes financiamentos, instituições, profissões e diversos aliados não humanos. São tantos recursos e aliados que refutar uma alegação ou "caixa preta" se torna uma tarefa quase impossível, ao mesmo tempo em que se torna fato ou realidade, resistindo a todos os esforços de modificações. Com isso, segundo o autor, a principal característica da tecnociência é a de se configurar como uma rede, possuindo perfil de contradições: é algo poderoso e pequeno, concentrado e diluído, ou seja, é forte porque emprega um número enorme de aliados, e é frágil e rara, pois só ouvimos falar 
quando todos os aliados estão presentes. Os nós nas redes significam que os recursos estão concentrados em poucos locais e se interligam aos fios das redes. De maneira mais ampla, essa contradição faz alusão a como poucas pessoas podem parecer "cobrir" o mundo, ou seja, apenas os cientistas e os seus aliados sejam os formadores dos fatos, ou caixas pretas. Mas então, o que acontece com as pessoas que estão por entre as malhas da rede, aquelas que não produzem tecnociência, mas que devem compor suas redes, de modo a acreditarem, discutirem, provarem e se apropriarem das caixas pretas? Como essas pessoas lidam com essa "realidade"?

Ao dizer que "muito disso é real, sabe por quê? Porque eu já vi acontecendo", Ivana discorda da hegemonia da explicação científica como uma "caixa preta", reafirmando outros modos de existência, outros sistemas de conhecimento, fortalecendo sua identidade camponesa. Discordar, neste caso, implicou em translações que se desviaram do sistema de conhecimento científico, mas mostraram possibilidades de se conviver com várias explicações ao mesmo tempo. Conforme se vê no relato de Iara:

Para mim o que é científico eu utilizo em lugares, por exemplo... dentro da minha comunidade:: aconteceu com um professor nosso da física que ele tentou colocar de qualquer forma na cabeça dos mais velhos de lá:: que o científico era o que tinha que ser e o que os mais velhos acreditavam não existia, isso acabou com a prática do ensino dele, porque ele nem quis voltar, no mesmo dia ele foi embora:: ele não quis ficar porque ele tentou de toda forma impor que as pessoas tinham que esquecer o que era mantido na comunidade... que é uma cultura... que era um costume deles de manter e esquecer aquilo e aprender só o que a astronomia mandava, e:: que a questão de lu::a que, o que os antepassados passavam era mentira e:: na verdade é só o que de certa forma o saber científico traz, então para mim assim, eu trato o científico em momentos diferentes do que... mas sem deixar de lado o que eu carrego dos meus antepassados, eu carrego os dois, tanto o científico, como o popular mas tipo que uma coisa que para mim faz todo sentido porque eu vivenciei isso e ainda vivencio é essas questões da fase da lua, então quando o professor falou que isso não existe, eu falei: tudo bem! Sua física não explica, mas o meu cotidiano, a minha história e a história de centenas de ancestrais meus e de centenas, de milhões de seres humanos que já passou (sic) pela Terra e que faz isso até hoje, já me explica, então pronto! (Iara)

$\mathrm{Na}$ fala da Iara, percebemos um julgamento de irracionalidade do professor ao querer impor o conhecimento científico como o único viável, lógico e racional. Latour (2000) faz uma crítica ao contexto de racionalidade e irracionalidade dos sistemas de conhecimento. Para ele, na visão da racionalidade científica existem pessoas que possuem acesso à natureza dos fenômenos e as que possuem visões distorcidas dos fenômenos. Para os primeiros, as que possuem as visões distorcidas dos fenômenos percorriam o caminho reto, ou lógico, mas houve um desvio em algum momento, por 
algum motivo, que as direcionaram para um discurso de irracionalidade ou de falta de lógica. E esses motivos são normalmente associados a fatores sociais, psicológicos, culturais, raciais, de gênero, dentre outros. Isso implica dizer que, se esses motivos forem eliminados, as demais pessoas seguiriam a mente sã dos cientistas e abririam mão das suas "crenças tortas". Nessa perspectiva, seria possível afirmar que os indivíduos da comunidade referida no relato poderiam seguir o conceito científico não fossem a atuação dos diversos motivos apontados como exemplos. Ao considerar esse raciocínio, Latour (2000) ressalta que não existem “crenças tortas” ou irracionais, mas que, por trás de todo sistema de conhecimento existe uma lógica. E todo julgamento de irracionalidade ocorre porque a observação é realizada a partir de outra crença. Os choques e acusações ocorrem quando há intersecções entre os caminhos dos grupos acusados e acusadores. Uma vez que o conceito de lógica passa a ficar atrelado ao grupo ou crença que se constitui, o conceito de lógica passa para o de sociológica, ou seja, corresponde ao tamanho da rede e aos elementos associados a ela. O que torna uma alegação ou um conhecimento forte ou fraco é a revelação na rede, das provas de força as quais revelam os seus elos fortes ou fracos.

Com isso, ao mapear a rede associada aos conhecimentos, sejam científicos ou tradicionais, ancestrais ou populares, podemos verificar o número de aliados que ajudaram a construí-la, às conexões que a compõem. Em outras palavras, o que determina a força de uma alegação não é o discurso de lógica ou racionalidade, mas sim da extensão ou tamanho da rede. Quanto maior a rede, mais aliados, mais associações e mais forte se torna a alegação. No caso de Iara, o conhecimento ancestral referente à influência da lua na vida cotidiana entra em conflito com o conhecimento científico. Ela se apoia na racionalidade camponesa e o professor de física, na racionalidade científica. Os sistemas de conhecimentos se chocam e não conseguem estabelecer um diálogo. As conexões da rede dos conhecimentos tradicionais, neste caso, são mais fortes e numerosas, resistindo às provas de força dos seus discordantes.

\section{CONSIDERAÇÕES FINAIS}

De um modo geral, a TAR nos permite elucidar a complexidade da rede de atores, das alianças, das translações que se dão na área de Ensino de Ciências na Educação do Campo. A constituição do projeto da Educação do Campo, na sua idealização, tem precisado de alianças e negociações para serem postas em sua prática institucionalizada, 
sofrendo translações que, como vimos nas análises, ora distanciam-se do projeto emancipatório dos povos do campo, ora geram interessantes situações de aprendizagem aos sujeitos do campo, sejam estudantes da LEC ou membros das comunidades. Aprendizagens que a partir dos dados supomos também acontecem com os professores, pesquisadores e gestores da educação superior, porém essa é uma questão com potencial analítico para outros trabalhos. Durante as análises constatamos as agências de diversos atores humanos: estudantes, professores, e principalmente a comunidade. Esta é uma diferença que nos parece importante entre a LEC e outras licenciaturas de ciências: entram na rede os movimentos sociais e os sujeitos do campo, que ajudam a estender e fortalecer esta rede. Em relação aos actantes não-humanos identificamos sobretudo os três elementos que definimos no início do trabalho, que caracterizam o foco da nossa pesquisa: (i) educação contextualizada, (ii) diálogo entre conhecimentos tradicionais e científicos e (iii) Pedagogia da Alternância. A Pedagogia da Alternância traz na rede metodologias de ensino, ou seja, tecnologias, que buscam colocar em diálogo os diferentes sistemas de conhecimentos e permitem fazer abordagens contextualizadas do Ensino de Ciências na perspectiva freireana. Nas análises encontramos translações que provocaram deslocamentos do projeto emancipatório da Educação do Campo no Ensino de Ciências, associações que tem origens nas diferentes tendências da área de Ensino de Ciências, que por vezes resultam em tensões e conflitos epistemológicos, como os julgamentos de irracionalidade que identificamos. Por outro lado, também identificamos que actantes não humanos, os artefatos educacionais, como a disciplina Práticas de Ensino e o Tempo Comunidade, criaram condições favoráveis para translações que consolidam interações e articulações entre conhecimentos científicos e tradicionais, não apenas nos estudantes da LEC, mas também nas famílias dos estudantes e nas comunidades do campo.

\section{REFERÊNCIAS BIBLIOGRÁFICAS}

BARBOUR, R. Grupos Focais. Porto Alegre: Artmed, 2009.

CALDART, R. S. Educação do Campo: Notas para uma Análise de Percurso.

Trabalho, Educação e Saúde, Rio de Janeiro, v.7, n. 1, 2009, p. 35-64.

CALLON, M. "Teoria da rede de atores, o teste de mercado" In: Law, J. e Hassard, J. (edições). Teoria Ator-Rede e Depois. Londres. Blackwell. 1999.

COMPIANI.(Org) Ribeirão Anhumas na Escola: Projeto de Formação Continuada Elaborando Conhecimentos Escolares relacionados à Ciência, à Sociedade e ao Ambiente. Curitiba, Editora CRV. 2013. 
DELIZOICOV, D.; ANGOTTI, J.A.; PERNANBUCO, M.M. Ensino de ciências: fundamentos e métodos. 4 ed. São Paulo. Editora Cortez. 2011.

BRASIL. Ministério da Educação. Conselho Nacional de Educação. Comissão de Educação Básica. Resolução n.1 de 03 de abril de 2002, estabelece Diretrizes para a Educação Básica nas escolas do campo, publicada no Diário Oficial da União. BrasíliaDF: Gráfica do Senado, em 09 de abril de 2002.

FENWICK, T.; EDWARDS, R. (Ed.). Researching education through actor-network theory. John Wiley \& Sons, 2012.

FREIRE, L.L. Seguindo Bruno Latour: notas para uma antropologia simétrica. Comum. Rio de Janeiro, v.11, no 26, p. 46- 65, jan./jun 2006.

FREIRE, P. Pedagogia do Oprimido. $45^{\mathrm{a}}$ ed. Rio de Janeiro: Paz e Terra. 2005.

LATOUR, B. Jamais fomos modernos: ensaio de Antropologia simétrica. (Trad. Carlos Irineu da Costa) Rio de Janeiro: Ed.34, 1994.

Ciência em ação: como seguir cientistas e engenheiros sociedade afora. São Paulo: UNESP, 2000.

. A esperança de Pandora: ensaios sobre a realidade dos estudos científicos. São Paulo: EDUSC, 2001.

Whose Cosmos, Which Cosmopolitics? Comments on the Peace Terms of Ulrich Beck. Common Knowledge, v. 10, n. 3, 2004, p. 450-462.

Reagregando o Social. Uma introdução à teoria ator-rede.

Salvador/Bauru: EDUFBA/EDUSC, 2012.

MOLINA, M.C. (Org.) Licenciaturas em Educação do Campo e o Ensino de Ciências naturais: desafios à promoção do Trabalho Docente Interdisciplinar. Brasilia: MDA. 2014.

MORAES, M. A ciência como rede de atores: ressonâncias filosóficas. História, Ciências, Saúde - Manguinhos, Rio de Janeiro, v.11, n.2, p.321-333, 2004. Disponível em http://www.scielo.br/scielo.php?script=sci_arttext\&pid=S0104-

$59702004000200006 \& \operatorname{lng}=$ en\&nrm=iso . Acesso em 10 Jun. 2015.

ORTEGA, O. COMPIANI, M. Caminhos em direção para uma CTS baseada no lugar. Anais do VIII Encontro Nacional de Pesquisa em Ensino de Ciências - ENPEC. 2011.

PERNAMBUCO, M. A.; PAIVA, I.A. (Org.) Práticas Coletivas na Escola. Campinas: Mercado das Letras, 2013.

RODRIGUES, João Assis. Práticas discursivas de reprodução e diferenciação na Pedagogia da Alternância. Tese de Doutorado. Universidade Federal do Espírito Santo. Vitória, 2008.

SILVA, F.N.S.; LIMA, L.R.F.C.; MORADILLO, E.F.; MASSENA, E.P. Educação do campo e ensino de ciências no Brasil: uma revisão dos últimos dez anos. Revista

Brasileira de Ensino de Ciências e Tecnologias. Ponta Grossa, v.12, n.1, p 221-239, jan./abr. 2019. 
Dossiê Educação do Campo e suas Interfaces com o Ensino de Ciências

SILVEIRA, C.; MIRANDA, A. C. Tendências das pesquisas da Educação do Campo a partir da análise de publicações nos anais do ENPEC. Revista Insignare Scientia -

RIS, v. 2, n. 2, p. 76-99, 16 set. 2019.

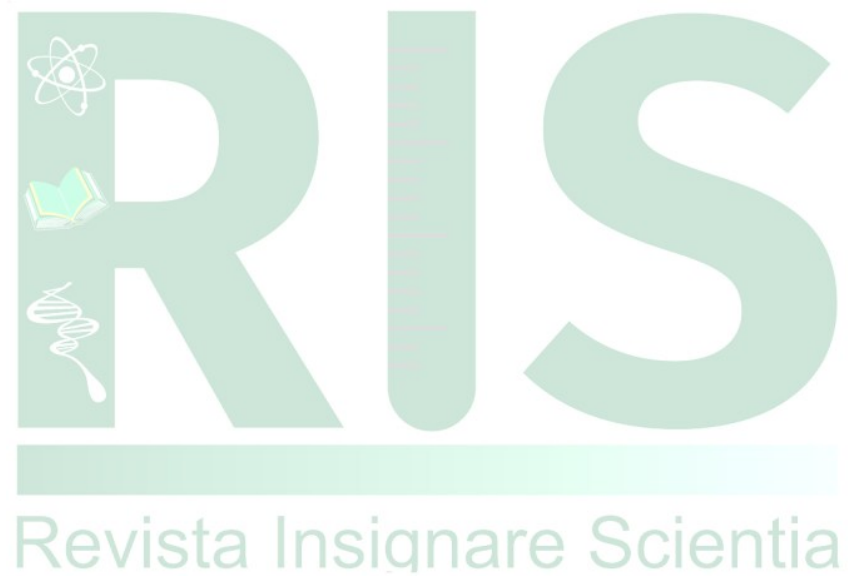

